\title{
Evaluation of factors associated with platinum-sensitivity status and survival in limited-stage small cell lung cancer patients treated with chemoradiotherapy
}

\author{
Qiang Wen ${ }^{1,2}$, Xue Meng ${ }^{1,2}$, Peng Xie ${ }^{1,2}$, Shijiang Wang ${ }^{1,2}$, Xindong Sun ${ }^{1,2}$ and Jinming $\mathbf{Y u}^{1,2}$ \\ ${ }^{1}$ Department of Radiation Oncology, Shandong Cancer Hospital Affiliated to Shandong University, Shandong University, \\ Jinan, 250117, China \\ ${ }^{2}$ Shandong Academy of Medical Sciences, Jinan, 250117, China
}

Correspondence to: Jinming Yu, email: sdyujinming@163.com

Keywords: small cell lung cancer, refractory, platinum-sensitivity status, survival, chemoradiotherapy

Received: January 04, 2017

Accepted: June 27, 2017

Published: July 07, 2017

Copyright: Wen et al. This is an open-access article distributed under the terms of the Creative Commons Attribution License 3.0 (CC BY 3.0 ), which permits unrestricted use, distribution, and reproduction in any medium, provided the original author and source are credited.

\section{ABSTRACT}

In this retrospective study, we analyzed the association of clinicopathological factors and therapeutic plans with platinum-sensitivity status and survival of limitedstage small cell lung cancer (LS-SCLC) patients. We enrolled 452 LS-SCLC patients with 279 platinum sensitive and 173 platinum refractory patients. The low serum neuro-specific enolase levels (NSE; $p=0.011$ ), neutrophil-to-lymphocyte ratios $(N L R ; p=0.013)$ and higher objective response rates $(p=0.003)$ were associated with sensitive group but not the refractory group. Multivariate analysis showed that treatment modality $(H R=0.267, p<0.001)$, serum lactate dehydrogenase (LDH; HR $=1.894, p=0.016), N L R(H R=2.043, p=0.043)$ and platinum-sensitivity status ( $H R=0.561, p=0.036$ ) were independent prognostic factors for survival. We further showed that the numbers of chemotherapy cycles and response to first-line therapy were independent prognostic factors for refractory patients only. Our study demonstrates that platinum-sensitivity status is of prognostic importance, as it is strongly associated with survival in LS-SCLC patients.

\section{INTRODUCTION}

Nearly $13 \%-20 \%$ of lung cancer cases are small cell lung cancer (SCLC) [1], which have high incidence of widespread metastasis [2]. About 30\% SCLC patients are diagnosed as limited disease (LD) and $70 \%$ as extensive disease (ED) [3]. Although patients with limited stage small-cell lung cancer (LS-SCLC) respond well to a combination of chemo- and radio-therapy, high recurrence rates result in low survival $[4,5]$. The recurrent cancer is generally refractory to therapy due to drug-resistant cancer cells and remains a problem for LS-SCLC survival [6].

LS-SCLC patients are denoted as platinum refractory or platinum sensitive based on shorter or longer relapse times (90 days from last platinum administered), respectively [7]. Patients with longer treatment-free interval generally demonstrate objective response (OR) to the same chemotherapy regimens used in initial treatment [8-10]. According to the National Comprehensive Cancer Network (NCCN 2016 edition) guidelines, the chosen second-line chemotherapy regimens [11] and the objective response rate (ORR) of second-line treatment were mainly dependent on the length of time from the end of chemotherapy to disease progression [12]. Although platinum-sensitivity status is important in clinical treatments, the risk factors in LS-SCLC are not known.

The circulating tumor cells (CTC) [13] and molecular factors such as vascular endothelial growth factor (VEGF) are widely considered as independent indicators for LS-SCLC survival [14]. However, the association between sensitivity to platinum-based treatment and overall survival is unclear [15]. Therefore, in this retrospective study, we evaluated the correlation of various clinicopathological factors with the platinumsensitivity status and overall survival of LS-SCLC patients.

\section{RESULTS}

\section{Patient characteristics}

The characteristics of patients were summarized in Table 1 . We enrolled 452 LS-SCLC patients with a 
median follow-up of 35.1 months. Among these, 279 patients were platinum sensitive and 173 patients were platinum refractory. The median age was 56 years (range: $27-82$ years) and $75.2 \%$ of patients were male. Eastern Cooperative Oncology Group performance status (ECOG PS) score was $0-1$ for 357 patients $(79 \%)$ and 2-3 for 95 patients $(21 \%) .71 .2 \%$ patients had smoking history and $86.3 \%$ of these patients smoked more than 30 pack-years.

In regard to therapeutic variables, $82.5 \%$ patients underwent chemoradiotherapy (including concurrent/ sequential chemoradiotherapy) and only $17.5 \%$ patients underwent chemotherapy alone. All 452 patients underwent platinum-based chemotherapy including 376 (83.2\%) with etoposide and $76(16.8 \%)$ with irinotecan. $87.6 \%$ patients received at least four cycles of chemotherapy.

\section{Univariate analysis of clinical factors associated with platinum-sensitivity status}

The comparison of clinical variables in the platinum sensitive and refractory patient groups is shown in Table 2. Univariate analysis showed that ECOG PS scores were better in the sensitive patients compared to refractory patients ( $0-1$ in sensitive vs. $0-1$ in refractory, $81.7 \%$ vs. $74.6 \%, p=0.070$ ). The objective response (complete plus partial responses) was also higher in the sensitive patients compared to refractory patients $(75.3 \%$ in sensitive vs. $60.7 \%$ in refractory, $p=0.001)$. Furthermore, more number of sensitive patients received chemoradiotherapy compared to the refractory group $(85.3 \% \mathrm{vs} .78 .0 \% p=0.048)$. The tumor size $(p=0.149)$ and white blood counts (WBC; $p=0.306$ ) were statistically similar between the two groups of patients. The neuro-specific enolase (NSE) levels were lower in the sensitive patients compared to refractory patients (44.44 vs. 52.26 at diagnosis, $p=0.004 ; 17.96$ vs. 23.16 after four cycles of chemotherapy, $p<0.001$; and 50.27 vs. 62.45 at progression, $p<0.001)$. Also, the neutrophil-to-lymphocyte ratios (NLR) were lower in the sensitive group compared to the refractory group (3.83 vs. $4.66, p=0.003$ at diagnosis; 2.45 vs. 4.1 after four cycles of chemotherapy, $p<0.001 ; 4.12$ vs. $5.11, p=0.003$ at progression).

\section{Multivariate analysis of clinical factors associated with platinum-sensitivity status}

Multivariate analysis demonstrated that among all the factors analyzed, only NSE, NLR and objective response correlated with the platinum-sensitivity status (Table 3). Objective response was an independent factor associated with platinum sensitive patients $(\mathrm{OR}=0.375$, 95\% CI: [0.195, 0.722]; $p=0.003)$. Meanwhile, NSE levels and NLR ratios at diagnosis ( $p=0.011, p=0.013)$, after four cycles of chemotherapy $(p<0.001, p=0.002)$ and at the time of progression $(p<0.001, p=0.030)$ were independent factors associated with platinum-sensitivity status. The other clinical parameters including ECOG
PS $(\mathrm{OR}=2.221,95 \%$ CI $[0.681,7.249] ; p=0.186)$ and treatment modality $(\mathrm{OR}=0.647,95 \% \mathrm{CI}[0.215,1.953]$; $p=0.440$ ) were not associated with platinum sensitivity (Table 3).

We then compared mean NLR and platelet-tolymphocyte ratio (PLR) to disease status (Table 4). In platinum-sensitive group, NLR decreased from 3.83 to $2.45(p<0.001)$ after four cycles of chemotherapy, and then increased to $4.12(p<0.001)$ at progression. In the refractory group, NLR decreased from 4.66 to 4.10 $(p=0.03)$, but sharply increased to 5.11 at progression $(p=0.006)$. PLR also demonstrated similar trend in the two patient groups, although the differences were not significant when compared in terms of disease status (Table 4).

\section{Prognostic factors for LS-SCLC survival}

The median overall survival (OS) of LS-SCLC patients was 19.7 months and median progression-free survival (PFS) was 10.4 months. Platinum-sensitivity status affected survival and PFS rates differentially. The platinum sensitive group demonstrated better survival than the refractory group (21.1 months vs.16.8 months, log rank $p<0.001$, Figure 1). The PFS rates were also better for the sensitive group in comparison to the refractory patients (13.2 months vs. 8.4 months, $\log \operatorname{rank} p<0.001$, Figure 2).

Univariate analysis showed that treatment modality $(p<0.001)$, number of chemoradiotherapy cycles $(p=0.005)$, lactate dehydrogenase (LDH) $(p=0.001)$, platinum-sensitivity status $(p<0.001)$, NSE $(p=0.065)$, $\operatorname{NLR}(p=0.004)$ and PLR $(p=0.016)$ were associated with survival. Multivariate analysis revealed that patients that received combined treatment showed increased OS compared to chemotherapy alone $(\mathrm{HR}=0.267,95 \% \mathrm{CI}$ $[0.128,0.555] ; p<0.001)$. Furthermore, high serum LDH levels $(\mathrm{HR}=1.894,95 \%$ CI $[1.124,3.193] ; p=0.016)$ and NLR levels $(\mathrm{HR}=2.043,95 \%$ CI [1.017-4.098]; $p=0.043$ ) were independent negative prognostic factors of survival. The platinum sensitive patients correlated with better overall survival (HR $=0.56195 \%$ CI [0.327-0.962], $p=0.036$; Table 5).

Similarly, patients with high serum LDH $(p=0.008), \operatorname{NSE}(p=0.02)$ and $\operatorname{NLR}(p=0.016)$ demonstrated decreased PFS rate. Among treatmentrelated variables, patients with chemoradiotherapy showed better PFS than chemotherapy alone (11.6 months vs. 7.0 months, $p<0.001)$. Also, no less than four cycles of chemotherapy $(p<0.001)$, platinum sensitive group $(p<0.001)$ and best response to initial chemotherapy $(p=0.021)$ were all favorable factors for PFS (Table 5).

\section{Subgroup analysis of clinical factors associated with survival}

In subgroup analysis, numbers of chemotherapy cycles $(\mathrm{HR}=0.515,95 \%$ CI $[0.306,0.865], p=0.012)$, 


\begin{tabular}{|c|c|c|}
\hline Characteristics & Number of patients & Percentage \\
\hline \multicolumn{3}{|l|}{ Gender } \\
\hline Male & 340 & $75.2 \%$ \\
\hline Female & 112 & $24.8 \%$ \\
\hline \multicolumn{3}{|l|}{ Age } \\
\hline$<65$ & 292 & $64.6 \%$ \\
\hline$\geq 65$ & 160 & $35.4 \%$ \\
\hline \multicolumn{3}{|l|}{ ECOG PS } \\
\hline $0-1$ & 357 & $79.0 \%$ \\
\hline $2-3$ & 95 & $21.0 \%$ \\
\hline \multicolumn{3}{|l|}{ Smoking Status } \\
\hline Yes & 322 & $71.2 \%$ \\
\hline No & 130 & $28.8 \%$ \\
\hline \multicolumn{3}{|l|}{ Smoking packs } \\
\hline$\geq 30$ packs-year & 278 & $86.3 \%$ \\
\hline$<30$ packs-year & 44 & $13.7 \%$ \\
\hline \multicolumn{3}{|l|}{ Treatment modality } \\
\hline Chemoradiotherapy & 373 & $82.5 \%$ \\
\hline Chemotherapy alone & 79 & $17.5 \%$ \\
\hline \multicolumn{3}{|l|}{ Chemoradiotherapy } \\
\hline Concurrent & 303 & $81.2 \%$ \\
\hline Sequential & 70 & $18.8 \%$ \\
\hline \multicolumn{3}{|l|}{ Treatment regimen } \\
\hline Etoposide + platinum & 376 & $83.2 \%$ \\
\hline Irinotecan + platinum & 76 & $16.8 \%$ \\
\hline \multicolumn{3}{|l|}{ Chemotherapy cycles } \\
\hline $\mathrm{N} \geq 4$ & 396 & $87.6 \%$ \\
\hline $\mathrm{N}<4$ & 56 & $12.4 \%$ \\
\hline \multicolumn{3}{|l|}{ Therapy response } \\
\hline $\mathrm{CR}+\mathrm{PR}$ & 315 & $69.6 \%$ \\
\hline $\mathrm{SD}+\mathrm{PD}$ & 137 & $30.3 \%$ \\
\hline \multicolumn{3}{|l|}{ WBC } \\
\hline Normal $(<10 / \mathrm{nl})$ & 302 & $70.9 \%$ \\
\hline Elevated ( $\geq 10 / \mathrm{nl})$ & 124 & $29.1 \%$ \\
\hline \multicolumn{3}{|l|}{ LDH } \\
\hline Normal $(<240 \mathrm{U} / 1)$ & 299 & $69.1 \%$ \\
\hline Elevated $(\geq 240 \mathrm{U} / \mathrm{l})$ & 134 & $30.9 \%$ \\
\hline \multicolumn{3}{|l|}{ Hemoglobin } \\
\hline Nomal ( $\geq 110 \mathrm{~g} / \mathrm{l})$ & 342 & $85.7 \%$ \\
\hline Decreased $(<110 \mathrm{~g} / \mathrm{l})$ & 57 & $14.3 \%$ \\
\hline
\end{tabular}




$\begin{array}{lcc}\text { Normal }(\geq 135 \mathrm{mM}) & 339 & 76.5 \% \\ \text { Decreased }(<135 \mathrm{mM}) & 104 & 23.5 \% \\ \text { GLUT } & & 66.4 \% \\ \text { Normal } & 265 & 33.6 \% \\ \text { Elevated } & 134 & \\ \text { PLT } & & 77.9 \% \\ \text { Inside }\left(100-300 * 10^{9} / 1\right) & 339 & 22.1 \% \\ \text { Outside }\left(>300 * 10^{9} / \mathrm{L}\right) & 96 & \end{array}$

Abbreviations: ECOG PS: Eastern Cooperative Oncology Group performance status; CR: complete response; PR: partial response; SD: disease stable; PD: disease progression; WBC: white blood count; LDH: lactate dehydrogenase; Na: sodium; GLUT: $\gamma$-glutamyl transferase; PLT: platelet count.

objective response ( $\mathrm{HR}=0.683,95 \%$ CI $[0.512-0.906]$, $p=0.011$ ) were independent prognostic factors for refractory patients, but not for sensitive patients (Table 6). Elevated NLR and NSE level, less than four cycles of chemotherapy, chemotherapy alone and resistance to firstline treatment in both groups demonstrated poor PFS. LDH levels did not correlate with PFS in refractory LSSCLC patients $(p=0.382$; Table 7).

\section{DISCUSSION}

In this retrospective study of LS-SCLC patients, we evaluated the correlation between clinical test results and factors with platinum-sensitivity status and survival. Our analysis revealed that NSE, NLR and objective response were independent predictors of platinum-sensitivity status. Prognostic factors for survival included treatment modality, LDH, NLR and platinum-sensitivity status.

While the first-line treatment guidelines are clear, there is ambiguity regarding treatment for relapsed LS-SCLC patients. Ardizzoni et al. demonstrated that response to the second-line drug, topotecan, was 38\% and $10 \%$ in sensitive and refractory patients, respectively [16]. In the latest meta-analysis, Horita et al. demonstrated that topotecan response rates for sensitive and refractive patients were $17 \%$ and $5 \%$ and the corresponding one-year OS rates were $27 \%$ and $9 \%$, respectively [17]. Therefore, distinguishing sensitive and refractory LS-SCLC patients early could result in therapeutic benefits.

NSE levels are associated with response to therapy, disease stage and overall survival and it can be used to monitor disease progression and recurrence. Yan et al demonstrated that survival rates were significantly different between low and high NSE level groups in small cell carcinoma of esophagus [18]. The histological characteristic of small cell carcinoma of esophagus was similar to SCLC. Therefore, our data showed that the sensitivity of platinum-based chemoradiotherapy was associated with serum NSE levels before treatment.
Recently, a series of inflammatory factors, such as NLR, PLR and C-reactive protein (CRP) were shown to be correlated with a poor prognosis in various types of cancer [19-21]. NLR was involved with tumor growth, invasion and metastasis through neutrophil elastase activity and suppression of the adaptive immune system $[22,23]$. However, NLR was not a stable tumor-specific biomarker since it was easily affected by treatment and radiation-induced inflammation [24, 25]. Therefore, some reports suggested that other inflammatory factors should be evaluated with NLR $[19,26]$. Furthermore, NLR levels always changed with treatment and disease courses [27]. Our results suggested that NLR was a critical parameter in evaluating tumor response and monitoring disease progression in LS-SCLC.

We also evaluated if therapeutic efficacy could distinguish sensitive and refractory patients. NagyMignotte et al. demonstrated complete response in $60.1 \%$ sensitive patient group compared to $9.7 \%$ in the refractory patient category [12]. Johnson et al. demonstrated effective response in $12.5 \%$ sensitive SCLC patients [28]. Therefore, NSE, NLR and objective response provide reliable and important predictive information about platinum-sensitivity status that would be helpful to weigh benefits of different treatments in the two groups.

Many studies have reported that good PS score, younger age and early stage are associated with survival benefit in LS-SCLC [29-31]. However, there is ambiguity due to variable biomarkers usage and analysis limitations. Some studies have suggested that radiotherapy in LSSCLC patients yields a 5-10\% improvement in two-year survival rate, and a corresponding $20 \%-35 \%$ increase in local control compared to chemotherapy alone [32, 33]. Our results indicated that patients with combined therapy were associated with decreased hazard ratios (HRs) compared to chemotherapy alone. Furthermore, many studies also suggested that early concurrent thoracic radiation was superior to late concurrent and sequential radiotherapy [34-36]. There was no association between sequential thoracic therapy and survival in our study, 
Table 2: Univariate analysis of relation between clinicopathological factors and platinum-sensitivity status in LS-SCLC

\begin{tabular}{|c|c|c|c|}
\hline Characteristics & Sensitive & Refractory & $p$ \\
\hline \multicolumn{4}{|l|}{ Gender } \\
\hline Male & $213(76.3 \%)$ & $127(73.4 \%)$ & 0.483 \\
\hline Female & $66(23.7 \%)$ & $46(26.6 \%)$ & \\
\hline \multicolumn{4}{|l|}{ Age } \\
\hline$<65$ & $187(67.0 \%)$ & $105(60.7 \%)$ & 0.171 \\
\hline$\geq 65$ & $92(33.0 \%)$ & $68(39.3 \%)$ & \\
\hline \multicolumn{4}{|l|}{ ECOG PS } \\
\hline $0-1$ & $228(81.7 \%)$ & $129(74.6 \%)$ & 0.07 \\
\hline $2-3$ & $51(18.3 \%)$ & $44(25.4 \%)$ & \\
\hline \multicolumn{4}{|l|}{ Smoking Status } \\
\hline Yes & $192(68.8 \%)$ & $130(75.1 \%)$ & 0.149 \\
\hline No & $87(31.2 \%)$ & $43(24.9 \%)$ & \\
\hline \multicolumn{4}{|l|}{ Smoking packs } \\
\hline$\geq 30$ packs-year & $128(87.1 \%)$ & $150(85.7 \%)$ & 0.723 \\
\hline$<30$ packs-year & $19(12.9 \%)$ & $25(14.2 \%)$ & \\
\hline \multicolumn{4}{|l|}{ Treatment modality } \\
\hline Chemoradiotherapy & $238(85.3 \%)$ & $135(78.0 \%)$ & 0.048 \\
\hline Chemotherapy alone & $41(14.7 \%)$ & $38(22.0 \%)$ & \\
\hline \multicolumn{4}{|l|}{ Chemoradiotherapy } \\
\hline Concurrent & $224(83.3 \%)$ & $79(76.0 \%)$ & 0.179 \\
\hline Sequential & $45(16.7 \%)$ & $25(24.0 \%)$ & \\
\hline \multicolumn{4}{|l|}{ Therapy regimen } \\
\hline Etoposide + platinum & $235(84.2 \%)$ & $141(81.5 \%)$ & 0.451 \\
\hline Irinotecan + platinum & $44(15.8 \%)$ & $32(18.5 \%)$ & \\
\hline \multicolumn{4}{|l|}{ Chemotherapy cycles } \\
\hline$N \geq 4$ & $250(89.6 \%)$ & $146(84.4 \%)$ & 0.102 \\
\hline$N<4$ & $29(10.4 \%)$ & $27(15.6 \%)$ & \\
\hline \multicolumn{4}{|l|}{ Response } \\
\hline $\mathrm{CR}+\mathrm{PR}$ & $210(75.3 \%)$ & $105(60.7 \%)$ & 0.001 \\
\hline $\mathrm{SD}+\mathrm{PD}$ & $69(24.7 \%)$ & $68(39.3 \%)$ & \\
\hline \multicolumn{4}{|l|}{ WBC } \\
\hline Normal $(<10 / \mathrm{nl})$ & $189(72.7 \%)$ & $113(68.1 \%)$ & 0.306 \\
\hline Elevated $(\geq 10 / \mathrm{nl})$ & $71(27.3 \%)$ & $53(31.9 \%)$ & \\
\hline \multicolumn{4}{|l|}{ LDH } \\
\hline Normal $(<240 \mathrm{U} / 1)$ & $193(71.5 \%)$ & $106(65.0 \%)$ & 0.159 \\
\hline Elevated $(\geq 240 \mathrm{U} / 1)$ & $77(28.5 \%)$ & $57(35.0 \%)$ & \\
\hline \multicolumn{4}{|l|}{ Hemoglobin } \\
\hline Normal ( $\geq 110 \mathrm{~g} / \mathrm{l})$ & $211(86.8 \%)$ & $131(84.0 \%)$ & 0.426 \\
\hline Decreased $(<110 \mathrm{~g} / \mathrm{l})$ & $32(13.2 \%)$ & $25(16.0 \%)$ & \\
\hline \multicolumn{4}{|l|}{$\mathbf{N a}$} \\
\hline Normal $(\geq 135 \mathrm{mM})$ & $208(75.9 \%)$ & $131(82.4 \%)$ & 0.699 \\
\hline Decreased $(<135 \mathrm{mM})$ & $66(24.1 \%)$ & $28(17.6 \%)$ & \\
\hline
\end{tabular}

GLUT 


\begin{tabular}{|c|c|c|c|}
\hline Normal ( $\leq 45$ U/1) & $158(65.0 \%)$ & $107(68.6 \%)$ & 0.461 \\
\hline Elevated $(>45 \mathrm{U} / 1)$ & $85(35.0 \%)$ & $49(31.4 \%)$ & \\
\hline \multicolumn{4}{|l|}{ PLT } \\
\hline Inside $\left(100-300 * 10^{9} / 1\right)$ & $208(78.8 \%)$ & $131(76.6 \%)$ & 0.592 \\
\hline Outside $\left(<100\right.$ or $\left.>300 * 10^{9} / 1\right)$ & $56(21.2 \%)$ & $40(23.4 \%)$ & \\
\hline Tumor Size & $50.78 \pm 20.58$ & $53.81 \pm 21.67$ & 0.149 \\
\hline BMI & $23.56 \pm 2.84$ & $23.13 \pm 2.89$ & 0.119 \\
\hline \multicolumn{4}{|l|}{ CEA } \\
\hline At diagnosis & $9.80 \pm 3.38$ & $10.38 \pm 3.89$ & 0.11 \\
\hline After four cycles & $8.09 \pm 2.75$ & $8.52 \pm 2.51$ & 0.184 \\
\hline At progression & $8.38 \pm 3.35$ & $8.94 \pm 3.06$ & 0.276 \\
\hline \multicolumn{4}{|l|}{ NSE } \\
\hline At diagnosis & $44.44 \pm 23.28$ & $52.26 \pm 25.58$ & 0.004 \\
\hline After four cycles & $17.96 \pm 7.54$ & $23.16 \pm 10.71$ & $<0.001$ \\
\hline At progression & $50.27 \pm 26.99$ & $62.45 \pm 33.60$ & $<0.001$ \\
\hline \multicolumn{4}{|l|}{ Cyfra21-1 } \\
\hline At diagnosis & $2.67 \pm 2.43$ & $3.07 \pm 2.37$ & 0.109 \\
\hline After four cycles & $1.86 \pm 1.34$ & $2.09 \pm 1.44$ & 0.215 \\
\hline At progression & $2.15 \pm 1.70$ & $2.41 \pm 1.56$ & 0.186 \\
\hline \multicolumn{4}{|l|}{ NLR } \\
\hline At diagnosis & $3.83 \pm 2.31$ & $4.66 \pm 2.82$ & 0.003 \\
\hline After four cycles & $2.45 \pm 1.67$ & $4.1 \pm 2.56$ & $<0.001$ \\
\hline At progression & $4.12 \pm 2.49$ & $5.11 \pm 3.09$ & 0.003 \\
\hline \multicolumn{4}{|l|}{ PLR } \\
\hline At diagnosis & $178.68 \pm 95.34$ & $186.18 \pm 109.55$ & 0.462 \\
\hline After four cycles & $170 \pm 95.31$ & $179.55 \pm 105.55$ & 0.362 \\
\hline At progression & $176.77 \pm 99.6$ & $184.83 \pm 98.89$ & 0.395 \\
\hline
\end{tabular}

Abbreviations: LS-SCLC: limited-stage small cell lung cancer; ECOG PS: Eastern Cooperative Oncology Group performance status; CR: complete response; PR: partial response; SD: disease stable; PD: disease progression; WBC: white blood count; LDH: lactate dehydrogenase; Na: sodium; GLUT: $\gamma$-glutamyl transferase PLT: platelet count; BMI: body mass index; CEA: carcino-embryonic antigen; NSE: neuro-specific enolase; NLR: neutrophil-to-lymphocyte ratio; PLR: platelet-to-lymphocyte ratio.

because it was more common in younger patients or patients with good condition (PS $<2$ ). Thirdly, radiation schedule and dose were still worthy to deeply analyze. Turrisi et al. concluded that patients that received radiotherapy twice-daily in 3 weeks showed better survival than those that received radiotherapy once-daily in 5 weeks (MST, 23 months vs. 19 months, $p=0.04$ ) [37]. High-dose radiotherapy (60 Gy) showed better survival and response rates compared to low-dose radiation therapy in the once-daily treatments [38-40].

Bremnes et al. concluded that LDH was an effective prognostic predictor in 219 patients with limited disease [41]. Moreover, Stokkel reported that LDH was an independent prognostic factor for tumor progression and patient survival [42]. However, Li et al. showed that high LDH levels were more frequent in advanced-stage SCLC patients and did not correlate with long-term survival [43]. Similarly, Brueckl et al. demonstrated that LDH was not associated with OS due to its high correlation with
WBC [44]. The differences among the results in these studies might be due to different approaches to measuring survival, disparate study designs or variables and sample sizes. Establishing an association between serum LDH level and SCLC progression would be beneficial to effectively monitoring therapy response, as previously shown $[45,46]$.

The prognostic role of NLR in LS-SCLC has not been investigated in detail. Kang et al. demonstrated that patients with low NLR $(\mathrm{NLR}<4)$ at diagnosis had relatively longer OS and PFS compared to those with high NLR ( $\geq 4$ ) [27]. However, Wang et al. did not find significant association between NLR and OS in LSSCLC [47]. Apart from assessing the prognostic role of NLR, the cut-off value of NLR is worth to be discussed. Some studies demonstrated significant correlation between NLR and overall survival with different cutoff values of NLR [20, 21]. Yamanaka et al. showed that advanced gastric cancer patients with low NLR $(<2.5)$ had better OS [48]. 
Table 3: Multivariate analysis of relation between clinicopathological factors and platinumsensitivity status in LS-SCLC

\begin{tabular}{lccc}
\hline Characteristics & OR & $\mathbf{9 5} \mathbf{C I} \%$ & $\boldsymbol{P}$ \\
\hline ECOG PS (PS 2-3) & 2.221 & $0.681-7.249$ & 0.186 \\
$\begin{array}{l}\text { Treatment modality } \\
\text { (Chemoradiotherapy) }\end{array}$ & 0.647 & $0.215-1.953$ & 0.440 \\
Response (CR + PR) & 0.375 & $0.195-0.722$ & 0.003 \\
NSE & & & \\
At diagnosis & 1.243 & $1.062-1.484$ & 0.011 \\
After four cycles & 2.726 & $2.035-3.684$ & $<0.001$ \\
At progression & 1.812 & $1.454-2.272$ & $<0.001$ \\
NLR & & & \\
At diagnosis & 1.703 & $1.054-2.757$ & 0.013 \\
After four cycles & 2.130 & $1.721-2.656$ & 0.002 \\
At progression & 1.743 & $1.056-2.747$ & 0.030 \\
\hline
\end{tabular}

Abbreviations: LS-SCLC: limited-stage small cell lung cancer; OR: Odds Ratio; CI: confidence interval; ECOG PS: Eastern Cooperative Oncology Group performance status; CR: complete response; PR: partial response; NSE: neuro-specific enolase; NLR: neutrophil-to-lymphocyte.

Table 4: Comparison of NLR and PLR at diagnosis, after four cycles of chemotherapy and at disease progression

\begin{tabular}{ccccccc}
\hline Factors & At diagnosis & After 4 cycles & $\boldsymbol{p}$ & After 4 cycles & Progression & $\boldsymbol{p}$ \\
\hline Sensitive & & & & & & \\
NLR & $3.83 \pm 2.31$ & $2.45 \pm 1.67$ & $<0.001$ & $2.45 \pm 1.67$ & $4.12 \pm 2.49$ & $<0.001$ \\
PLR & $178.68 \pm 95.34$ & $170 \pm 95.31$ & 0.335 & $170 \pm 95.31$ & $176.77 \pm 99.6$ & 0.52 \\
Refractory & & & & & & \\
NLR & $4.66 \pm 2.82$ & $4.1 \pm 2.56$ & 0.03 & $4.1 \pm 2.56$ & $5.11 \pm 3.09$ & 0.006 \\
PLR & $186.18 \pm 109.55$ & $179.55 \pm 105.55$ & 0.601 & $179.55 \pm 105.55$ & $184.83 \pm 98.89$ & 0.749 \\
\hline
\end{tabular}

Abbreviations: NLR: neutrophil-to-lymphocyte ratio; PLR: platelet-to-lymphocyte ratio.

We observed a clear cut survival benefit for platinum sensitive LS-SCLC patients. Von Pawel et al. reported that the sensitive group among the 637 SCLC patients that received topotecan or amrubicin had better median survival (Topotecan: 10 months vs. 5.7 months; Amrubicin: 9.2 months vs. 6.2 months) [49]. Garassion et al. considered that platinum-sensitivity status had significant effects on ORR ( $34.5 \%$ vs. $17.5 \%, p=0.06)$ and OS (9.2 months vs. 5.8 months, $p=0.08)$ of LS-SCLC patients [50]. However, there are some contradictory reports. Lara et al. investigated 3 clinical trials based on advanced stage SCLC and did not find association between platinum-sensitivity status and progression-free survival
(PFS) $(p=0.49)$ or overall survival (OS) $(p=0.14)$ [51]. This study used different methodologies for clinical staging and data collection compared to our study. Based on our data, we postulate that response to platinum-based chemotherapy is prognostic.

Adequate chemotherapy doses can significantly improve the short-term benefits and PFS of LS-SCLC patients. In the present study, we observed that patients treated with no less than four cycles of chemotherapy showed higher median survival although the data was not statistically significant in multivariate analysis. This could be because most of patients cannot tolerate six cycles of chemotherapy, especially concurrent chemoradiotherapy 


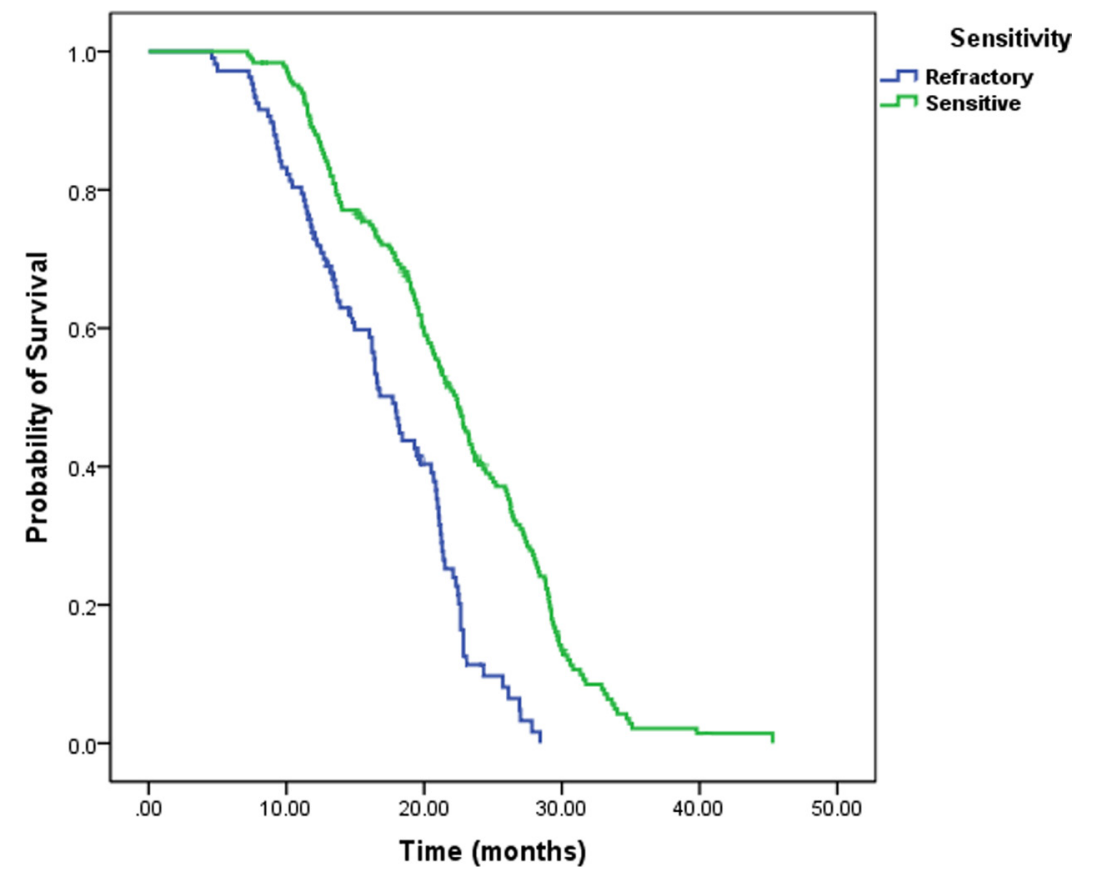

Figure 1: Kaplan-Meier analysis of OS for platinum-sensitivity status. Patients with platinum sensitive achieved longer OS than patients with platinum refractory.

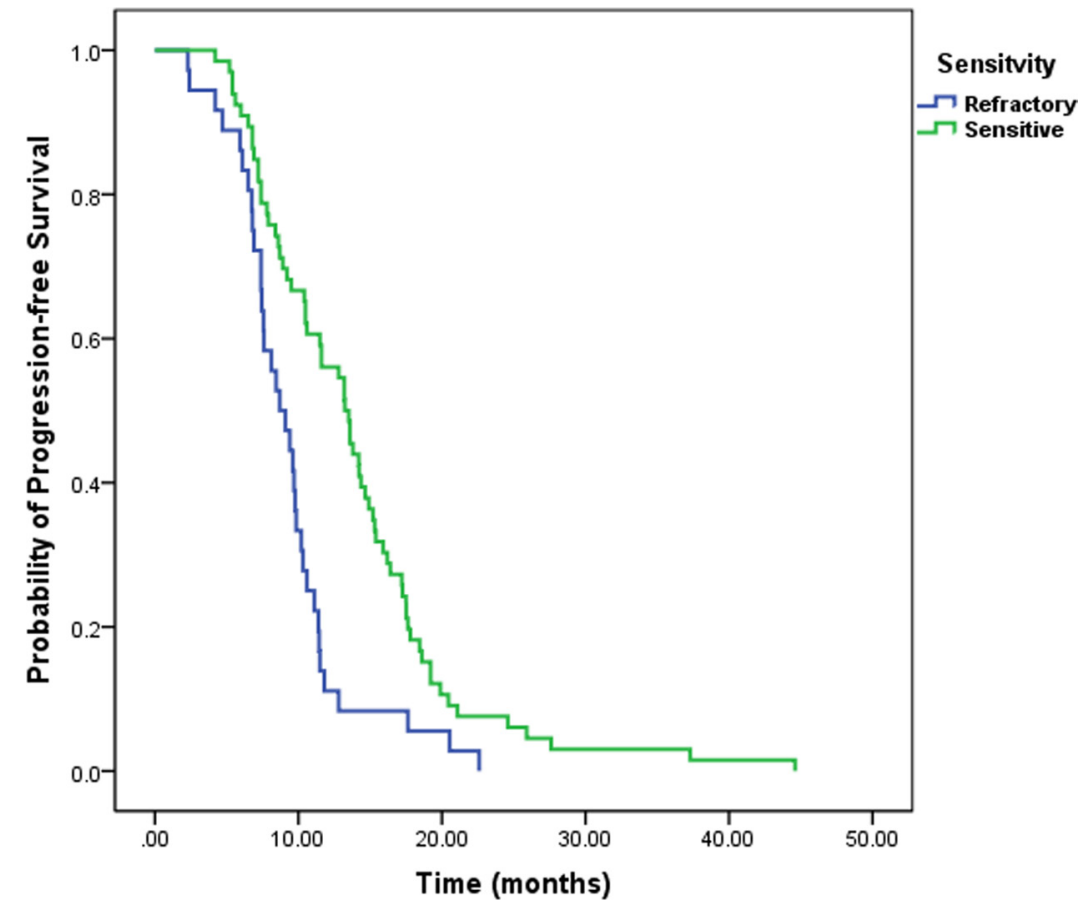

Figure 2: Kaplan-Meier analysis of PFS for platinum-sensitivity status. Patients with platinum sensitive had significant better PFS than patients with platinum refractory. 
Table 5: Multivariate analysis of prognostic factors associated with survival and PFS

\begin{tabular}{|c|c|c|c|c|c|c|}
\hline Characteristics & MST & HR $(95 \%$ CI $)$ & $p$ & PFS & HR $(95 \%$ CI $)$ & $p$ \\
\hline \multicolumn{7}{|l|}{ Numbers of cycle } \\
\hline$N \geq 4$ & 20.5 & $\begin{array}{c}0.753 \\
0.362-1.566\end{array}$ & 0.448 & 11.4 & $\begin{array}{c}0.271 \\
0.141-0.521\end{array}$ & $<0.001$ \\
\hline$N<4$ & 17.0 & Ref. & & 6.5 & Ref. & \\
\hline \multicolumn{7}{|l|}{ Treatment Modality } \\
\hline Chemoradiotherapy & 21.5 & $\begin{array}{c}0.267 \\
0.128-0.555\end{array}$ & $<0.001$ & 11.6 & $\begin{array}{c}0.349 \\
0.176-0.615\end{array}$ & $<0.001$ \\
\hline \multicolumn{6}{|l|}{ LDH } & \\
\hline Elevated (> $240 \mathrm{U} / \mathrm{l})$ & 17.5 & $\begin{array}{c}1.894 \\
1.124-3.193\end{array}$ & 0.016 & 7.5 & $\begin{array}{c}1.952 \\
1.195-3.188\end{array}$ & 0.008 \\
\hline $\begin{array}{l}\text { Normal }(\leq 240 \mathrm{U} / \mathrm{l}) \\
\text { NSE }\end{array}$ & 22.6 & Ref. & & 13.5 & Ref. & \\
\hline Elevated (> $18 \mathrm{ng} / \mathrm{ml})$ & 18.1 & $\begin{array}{c}1.373 \\
0.852-2.231\end{array}$ & 0.117 & 9.1 & $\begin{array}{c}1.513 \\
1.292-1.902\end{array}$ & 0.020 \\
\hline Normal $(\leq 18 \mathrm{ng} / \mathrm{ml})$ & 22.8 & Ref. & & 14.5 & Ref. & \\
\hline \multicolumn{7}{|l|}{ NLR } \\
\hline Elevated $(\geq 4)$ & 17.8 & $\begin{array}{c}2.043 \\
1.017-4.098\end{array}$ & 0.043 & 8.2 & $\begin{array}{c}1.748 \\
1.110-2.753\end{array}$ & 0.016 \\
\hline Normal $(<4)$ & 23.2 & Ref. & & 13.8 & Ref. & \\
\hline \multicolumn{7}{|l|}{ Platinum Status } \\
\hline Sensitive & 21.1 & $\begin{array}{c}0.561 \\
0.327-0.962\end{array}$ & 0.036 & 13.2 & $\begin{array}{c}0.333 \\
0.197-0.565\end{array}$ & $<0.001$ \\
\hline Refractory & 16.8 & Ref. & & 8.4 & Ref. & \\
\hline Response & & & & & & \\
\hline $\mathrm{CR}+\mathrm{PR}$ & 21.8 & $\begin{array}{c}0.592 \\
0.333-1.054\end{array}$ & 0.076 & 13.0 & $\begin{array}{c}0.384 \\
0.187-0.808\end{array}$ & 0.021 \\
\hline $\mathrm{SD}+\mathrm{PD}$ & 17.0 & Ref. & & 7.8 & Ref. & \\
\hline
\end{tabular}

Abbreviations: PFS: progression-free time; MST: median survival time; HR: hazard ratio; CI: confidence interval; LDH: lactate dehydrogenase; NSE: neuro-specific enolase; NLR: neutrophil-to-lymphocyte ratio; CR: complete response; PR: partial response; SD: disease stable; PD: disease progression.

due to serious side effects like gastrointestinal irritation and bone marrow suppression. Furthermore, long term chemotherapy before radiotherapy led to drug-resistant cancer cells that formed small distance metastases and reduced the efficiency of radiotherapy [52].

Subgroup analysis demonstrated that more than four cycles of chemotherapy and objective response to initial treatment were favorable prognostic factors only in refractory patients. This was probably due to different patient characteristics and response to successive lines of chemotherapy in two groups. The refractory group was mostly made up of elderly and poor PS patients, with greater reliance on chemotherapy cycle numbers and the drug dose. Nagy-Mignotte et al. showed that sensitive patients benefit more than refractory patients from subsequent therapy [12]. As a consequence, the response to initial therapy was critical in improving disease prognosis.

Serum LDH levels were related with PFS in the sensitive group, but not in the refractory group. Previous studies demonstrated that elevated LDH levels were associated with poor survival and chemo-/radio resistance in malignancies as they signified hypoxia inducible factor induced tumor aggressiveness [53].

Apart from basic clinical and laboratory factors, many molecular and genetic studies have explored novel prognostic factors that require invasive examinations and increase the economic burden on patients $[54,55]$. Our study suggested that routine laboratory test results are prognostic and can provide information for precision treatment. By identifying patients with sensitive disease, patients can be treated with lower total radiotherapy and chemotherapy doses to achieve good results. At the same time, patients that are more likely to progress can be switched to alternative treatments earlier to reduce high drug toxicity.

This study is limited because it is retrospective and due to heterogeneity of the characteristics and therapies administered in individual trials. Furthermore, confounding factors like race and socioeconomic status $[56,57]$, which were not taken into consideration in 
Table 6: Multivariate analysis of prognostic factors associated with survival in sensitive and refractory patients

\begin{tabular}{|c|c|c|c|c|c|c|}
\hline \multirow{2}{*}{ Variables } & \multicolumn{3}{|c|}{ Sensitive LS-SCLC } & \multicolumn{3}{|c|}{ Refractory LS-SCLC } \\
\hline & MST & HR (95\% CI) & $p$ & MST & HR $(95 \%$ CI $)$ & $p$ \\
\hline \multicolumn{7}{|l|}{ Numbers of cycle } \\
\hline$N \geq 4$ & 23.8 & $\begin{array}{c}0.598 \\
0.345-1.034\end{array}$ & 0.066 & 18.3 & $\begin{array}{c}0.515 \\
0.306-0.865\end{array}$ & 0.012 \\
\hline$N<4$ & 17.5 & Ref. & & 13.1 & Ref. & \\
\hline \multicolumn{7}{|l|}{ Response } \\
\hline $\mathrm{CR}+\mathrm{PR}$ & 24.5 & $\begin{array}{c}0.571 \\
0.309-1.068\end{array}$ & 0.083 & 18.4 & $\begin{array}{c}0.683 \\
0.512-0.906\end{array}$ & 0.011 \\
\hline $\mathrm{PD}+\mathrm{SD}$ & 17.1 & Ref. & & 14.2 & Ref. & \\
\hline \multicolumn{7}{|l|}{ Treatment Modality } \\
\hline Chemoradiotherapy & 24.7 & $\begin{array}{c}0.528 \\
0.315-0.878\end{array}$ & 0.016 & 18.0 & $\begin{array}{c}0.738 \\
0.552-0.943\end{array}$ & 0.023 \\
\hline Chemotherapy & 16.6 & Ref. & & 14.6 & Ref. & \\
\hline \multicolumn{7}{|l|}{ LDH } \\
\hline Elevated $(>240 \mathrm{U} / \mathrm{l})$ & 18.1 & $\begin{array}{c}2.610 \\
1.862-3.679\end{array}$ & $<0.001$ & 13.7 & $\begin{array}{c}2.313 \\
1.556-3.417\end{array}$ & $<0.001$ \\
\hline Normal ( $\leq 240 \mathrm{U} / 1)$ & 26.4 & Ref. & & 19.2 & Ref. & \\
\hline \multicolumn{7}{|l|}{ NLR } \\
\hline Elevated $(\geq 4)$ & 18.4 & $\begin{array}{c}1.538 \\
1.072-2.214\end{array}$ & 0.024 & 14.1 & $\begin{array}{c}1.677 \\
1.110-2.524\end{array}$ & 0.013 \\
\hline Normal $(<4)$ & 25.6 & Ref. & & 18.6 & Ref. & \\
\hline
\end{tabular}

Abbreviations: LS-SCLC: limited-stage small cell lung cancer; MST: median survival time; HR: hazard ratio; CI: confidence interval; CR: complete response; PR: partial response; SD: disease stable; PD: disease progression; LDH: lactate dehydrogenase; NLR: neutrophil-to-lymphocyte ratio.

this study. Also, the small number of patients and the single center study can result in intrinsic bias. Finally, since the radiotherapy technique is undergoing constant improvements, the platinum-sensitivity status between patients at different times is hard to compare in a retrospective study. Therefore, multi-center prospective study with larger patient pools is needed to confirm our results. In conclusion, our study demonstrates that platinum-sensitivity status is a critical prognostic factor that determines the survival rates in LS-SCLC patients.

\section{MATERIALS AND METHODS}

\section{Patient enrollment criteria}

We retrospectively enrolled LS-SCLC patients that were diagnosed by cytology or histology between January 2005 and December 2010 at Shandong Cancer Hospital and received at least one cycle of chemotherapy. The cytological or histological diagnosis of disease was performed by mediastinoscopy, bronchofiberoscopy and biopsy of lymph nodes. For all patients, standard evaluation before treatment included brain magnetic resonance imaging (MR), bone scintigraphy and CT imaging of chest and abdomen. Positron emission tomography-computed tomography (PET/CT) was not routinely performed. Tumor stage was determined according to the Veterans Administration Lung Study Group system [58]. This study was approved by the Research Ethics Committee of Shandong Cancer Hospital, China. Informed consent was obtained from all participants.

\section{Therapeutic treatment and tumor response}

Patients that did not receive standard therapeutic strategy were excluded from this study. The chemotherapy regimens included etoposide plus platinum and irinotecan plus platinum. Chemotherapy doses were modified based on individual toxicity levels and blood counts. Patients underwent radiotherapy either by 3-dimensional conformal radiotherapy (3D-CRT) or intensity modulated radiotherapy (IMRT). The gross tumor volume (GTV) included primary tumor and positive lymph nodes. The clinical tumor volume (CTV) was drawn from GTV with $8 \mathrm{~mm}$ margin. The planning target volume (PTV) was determined from GTV with less than $1.5 \mathrm{~cm}$ in 3D. 
Table 7: Multivariate analysis of prognostic factors associated with PFS in sensitive and refractory patients

\begin{tabular}{|c|c|c|c|c|c|c|}
\hline \multirow{2}{*}{ Variables } & \multicolumn{3}{|c|}{ Sensitive LS-SCLC } & \multicolumn{3}{|c|}{ Refractory LS-SCLC } \\
\hline & PFS & HR $(95 \%$ CI $)$ & $p$ & PFS & HR $(95 \%$ CI) & $p$ \\
\hline \multicolumn{7}{|l|}{ Numbers of cycle } \\
\hline$N \geq 4$ & 14.0 & $\begin{array}{c}0.329 \\
0.119-0.906\end{array}$ & 0.031 & 10.4 & $\begin{array}{c}0.289 \\
0.117-0.716\end{array}$ & $<0.001$ \\
\hline$N<4$ & 8.3 & Ref. & & 5.9 & Ref. & \\
\hline \multicolumn{7}{|l|}{ Treatment Modality } \\
\hline Chemoradiotherapy & 14.6 & $\begin{array}{c}0.283 \\
0.106-0.755\end{array}$ & 0.012 & 9.1 & $\begin{array}{c}0.316 \\
0.102-0.960\end{array}$ & 0.042 \\
\hline Chemotherapy & 7.8 & Ref. & & 6.2 & Ref. & \\
\hline \multicolumn{7}{|l|}{ LDH } \\
\hline Elevated (> $240 \mathrm{U} / \mathrm{l})$ & 8.5 & $\begin{array}{c}2.331 \\
1.211-4.486\end{array}$ & 0.001 & 7.0 & $\begin{array}{c}1.366 \\
0.678-2.753\end{array}$ & 0.382 \\
\hline Normal ( $\leq 240 \mathrm{U} / 1)$ & 15.3 & Ref. & & 9.0 & Ref. & \\
\hline \multicolumn{7}{|l|}{ NLR } \\
\hline Elevated $(\geq 4)$ & 9.2 & $\begin{array}{c}1.748 \\
1.110-2.753\end{array}$ & 0.016 & 6.7 & $\begin{array}{c}1.283 \\
1.088-1.546\end{array}$ & 0.037 \\
\hline Normal $(<4)$ & 15.4 & Ref. & & 9.4 & Ref. & \\
\hline \multicolumn{7}{|l|}{ NSE } \\
\hline Elevated (> 18 ng/ml) & 10.2 & $\begin{array}{c}1.513 \\
1.292-1.902\end{array}$ & 0.020 & 6.0 & $\begin{array}{c}1.723 \\
1.278-2.127\end{array}$ & $<0.001$ \\
\hline Normal $(\leq 18 \mathrm{ng} / \mathrm{ml})$ & 16.0 & Ref. & & 10.0 & Ref. & \\
\hline \multicolumn{7}{|l|}{ Response } \\
\hline $\mathrm{CR}+\mathrm{PR}$ & 15.0 & $\begin{array}{c}0.266 \\
0.116-0.614\end{array}$ & 0.002 & 9.3 & $\begin{array}{c}0.342 \\
0.163-0.718\end{array}$ & 0.006 \\
\hline $\mathrm{SD}+\mathrm{PD}$ & 8.7 & Ref. & & 6.0 & Ref. & \\
\hline
\end{tabular}

Abbreviations: LS-SCLC: limited-stage small cell lung cancer; PFS: progression-free time; HR: hazard ratio; CI: confidence interval; LDH: lactate dehydrogenase; NLR: neutrophil-to-lymphocyte ratio; NSE: neuro-specific enolase; CR: complete response; PR: partial response; SD: disease stable; PD: disease progression.

Patients with disease progression in less than 90 days after treatment were denoted as platinum refractory, whereas patients with disease progression at 90 or more days were identified as platinum sensitive. During chemotherapy, CT scan and the specific biomarkers of tumor were accessed and analyzed every two or three cycles to determine tumor response. Based on Response Evaluation Criteria in Solid Tumor (RECST) guidelines [59], tumor response to first-line treatment was subdivided into complete response (CR), partial response $(\mathrm{PR})$, stable disease (SD) and progression disease (PD).

\section{Follow-up and data collection}

The clinical data was obtained from medical records. Re-examinations included physical examination, tumor biomarkers, routine laboratory test, medication history and $\mathrm{CT}$ scan. Chest and abdomen $\mathrm{CT}$ imaging was performed one month after initial treatment, with follow-up every 2-3 months in the first year, then every sixth months, second year onwards. Brain MR and bone scintigraphy were not compulsory and were administered according to clinical requirements.

In this study, clinical and demographic indicators including age, gender, smoking status, ECOG PS and treatment modality were collected using medical record system at baseline. Also, routine laboratory tests that were obtained from patient records included WBC, hemoglobin (HB), PLT, LDH, sodium (Na), $\gamma$-glutamyl transferase (GLUT) at diagnose. Cyfra21-1, NSE, carcinoembryonic antigen (CEA), NLR and PLR were recorded at diagnosis, after four cycles of chemotherapy, and at the time of progression. The NLR was calculated from the differential counts by dividing the neutrophil number by the lymphocyte number. The PLR was calculated by dividing the platelet count by the lymphocyte count. 
The cutoff values of variables were determined using the clinical normal range and the related research results [27]. Parameters with more than $20 \%$ missing observations were excluded from the study.

\section{Statistical analysis}

Survival time was measured from the time of diagnosis to death or the last follow-up date. Progressionfree survival was determined from the time of therapy initiation to the time of disease progression or death. Date of recurrence was determined by the date of positive CT imaging results. The platinum-sensitivity status was determined based on the time between last platinum administrations to date of recurrence.

All statistical analyses were performed using SPSS software version 19.0 for windows (SPSS Inc., Chicago, IL, USA). Categorical variables were expressed as percentage and compared between groups using chi-square test. Continuous variables were presented as mean \pm standard deviation (s.d.) or median and range with a Mann-Whitey $U$ test performed for comparison. Variables with $p<0.1$ were considered statistically significant (two-sided). Logistic regression with backward stepwise method was used for multivariate analysis. Patient survival curves were measured by the Kaplan-Meier method and compared by log-rank test. Univariate Cox proportional hazard models were used to identify factors associated with survival and PFS. Multivariate Cox regression analyses were performed to determine the factors that were significant based on univariate analysis. Variables with $p<0.05$ were considered statistically significant (two-sided).

\section{Authors' contributions}

Q.W designed the study and wrote the manuscript. X.M participated in the study designing and data collection. SJ.W analyzed the data. P.X and XD.S participated in data collection and offered guidance. JM.Y carried out the study design and interpretation of data and drafted the manuscript. All authors read and approved the final manuscript.

\section{ACKNOWLEDGMENTS}

This study was supported by the special foundation for Scientific Research in Public Interest of China (Grant No. 201402011) and Shandong Provincial Key Project of Translational Medicine (Grant No.ZR2015HZ004). The funding sources had no role in the study design, data collection, analysis of interpretation, or the writing of this manuscript.

\section{CONFLICTS OF INTEREST}

The authors have no potential conflicts of interest relevant to the content of this manuscript.

\section{REFERENCES}

1. van Meerbeeck JP, Fennell DA, De Ruysscher DK. Smallcell lung cancer. The Lancet. 2011; 378:1741-55.

2. Bayman NA, Sheikh H, Kularatne B, Lorigan P, Blackhall F, Thatcher N, Faivre-Finn C. Radiotherapy for small-cell lung cancer-Where are we heading? Lung Cancer. 2009; 63:307-14.

3. Govindan R, Page N, Morgensztern D, Read W, Tierney R, Vlahiotis A, Spitznagel EL, Piccirillo J. Changing epidemiology of small-cell lung cancer in the United States over the last 30 years: analysis of the surveillance, epidemiologic, and end results database. Journal of clinical oncology. 2006; 24:4539-44.

4. Lally BE, Geiger AM, Urbanic JJ, Butler JM, Wentworth S, Perry MC, Wilson LD, Horton JK, Detterbeck FC, Miller AA. Trends in the outcomes for patients with limited stage small cell lung cancer: An analysis of the Surveillance, Epidemiology, and End Results database. Lung Cancer. 2009; 64:226-31.

5. El Maalouf G, Rodier JM, Faivre S, Raymond E. Could we expect to improve survival in small cell lung cancer? Lung Cancer. 2007; 57:S30-S4.

6. Gaspar LE, McNamara EJ, Gay EG, Putnam JB, Crawford J, Herbst RS, Bonner JA. Small-cell lung cancer: prognostic factors and changing treatment over 15 years. Clinical lung cancer. 2012; 13:115-22.

7. Giaccone G, Donadio M, Bonardi G, Testore F, Calciati A. Teniposide in the treatment of small-cell lung cancer: the influence of prior chemotherapy. Journal of Clinical Oncology. 1988; 6:1264-70.

8. Postmus PE, Berendsen HH, van Zandwijk N, Splinter TA, Burghouts JT, Bakker W. Retreatment with the induction regimen in small cell lung cancer relapsing after an initial response to short term chemotherapy. European Journal of Cancer and Clinical Oncology. 1987; 23:1409-11.

9. Giaccone G, Ferrati P, Donadio M, Testore F, Calciati A. Reinduction chemotherapy in small cell lung cancer. European Journal of Cancer and Clinical Oncology. 1987; 23:1697-9.

10. Vincent M, Evans B, Smith I. First-line chemotherapy rechallenge after relapse in small cell lung cancer. Cancer chemotherapy and pharmacology. 1988; 21:45-8.

11. Owonikoko TK, Behera M, Chen Z, Bhimani C, Curran WJ, Khuri FR, Ramalingam SS. A systematic analysis of efficacy of second-line chemotherapy in sensitive and refractory small-cell lung cancer. Journal of Thoracic Oncology. 2012; 7:866-72.

12. Nagy-Mignotte H, Guillem P, Vignoud L, Coudurier M, Vesin A, Bonneterre V, Toffart AC, Sakhri L, Brambilla C, Brambilla E. Outcomes in recurrent small-cell lung cancer after one to four chemotherapy lines: a retrospective study of 300 patients. Lung Cancer. 2012; 78:112-20.

13. Hou JM, Krebs MG, Lancashire L, Sloane R, Backen A, Swain RK, Priest LJ, Greystoke A, Zhou C, Morris K. 
Clinical significance and molecular characteristics of circulating tumor cells and circulating tumor microemboli in patients with small-cell lung cancer. Journal of Clinical Oncology. 2012; 30:525-32.

14. Lu HY, Wang XJ, Mao WM. Targeted therapies in small cell lung cancer (Review). Oncology letters. 2013; 5:3-11.

15. Chen J, Jiang R, Garces YI, Jatoi A, Stoddard SM, Sun Z, Marks RS, Liu Y, Yang P. Prognostic factors for limitedstage small cell lung cancer: a study of 284 patients. Lung Cancer. 2010; 67:221-6.

16. Ardizzoni A, Hansen H, Dombernowsky P, Gamucci T, Kaplan S, Postmus P, Giaccone G, Schaefer B, Wanders J, Verweij J. Topotecan, a new active drug in the second-line treatment of small-cell lung cancer: a phase II study in patients with refractory and sensitive disease. The European Organization for Research and Treatment of Cancer Early Clinical Studies Group and New Drug Development Office, and the Lung Cancer Cooperative Group. Journal of Clinical Oncology. 1997; 15:2090-6.

17. Horita N, Yamamoto M, Sato T, Tsukahara T, Nagakura H, Tashiro K, Shibata Y, Watanabe H, Nagai K, Inoue M. Topotecan for relapsed small-cell lung cancer: Systematic review and meta-analysis of 1347 Patients. Scientific reports. 2015; 5.

18. Yan $\mathrm{H}$, Wang $\mathrm{R}$, Jiang $\mathrm{S}$, Zhu $\mathrm{K}$, Feng $\mathrm{R}, \mathrm{Xu} \mathrm{X}$, Meng X. NSE can predict the sensitivity to definitive chemoradiotherapy of small cell carcinoma of esophagus. Medical Oncology. 2014; 31:1-7.

19. Yalcinkaya E, Bugan B, Celik M, Yasar S, Gursoy E. Neutrophil lymphocyte ratio should be assessed together with other inflammatory markers and confounding factors. European review for medical and pharmacological sciences. 2013; 17:2410.

20. Chua W, Charles K, Baracos V, Clarke S. Neutrophil/ lymphocyte ratio predicts chemotherapy outcomes in patients with advanced colorectal cancer. British journal of cancer. 2011; 104:1288-95.

21. Stotz M, Gerger A, Eisner F, Szkandera J, Loibner H, Ress A, Kornprat P, Zoughbi W, Seggewies F, Lackner C. Increased neutrophil-lymphocyte ratio is a poor prognostic factor in patients with primary operable and inoperable pancreatic cancer. British journal of cancer. 2013; 109:416-21.

22. Sun Z, Yang P. Role of imbalance between neutrophil elastase and alpha 1-antitrypsin in cancer development and progression. Lancet Oncology. 2004; 5:182-90.

23. Fridlender ZG, Sun J, Kim S, Kapoor V, Cheng G, Ling L, Worthen GS, Albelda SM. Polarization of TumorAssociated Neutrophil (TAN) Phenotype by TGF- $\beta$ : "N1" versus "N2" TAN. Cancer Cell. 2009; 16:183-94.

24. Tabuchi Y, Shinka S, Ishida H. The effects of anesthesia and surgery on count and function of neutrophils. Journal of anesthesia. 1989; 3:123-31.

25. Lorimore SA, Coates PJ, Scobie GE, Milne G, Wright EG. Inflammatory-type responses after exposure to ionizing radiation in vivo: a mechanism for radiation-induced bystander effects? Oncogene. 2001; 20:7085.

26. Nakamura $T$, Matsumine A, Matsubara T, Asanuma $K$, Uchida A, Sudo A. The combined use of the neutrophillymphocyte ratio and C-reactive protein level as prognostic predictors in adult patients with soft tissue sarcoma. Journal of Surgical Oncology. 2013; 108:481-5.

27. Kang MH, Go SI, Song H, Lee A, Kim S, Kang J, Jeong B, Kang K, Ling H, Lee G. The prognostic impact of the neutrophil-to-lymphocyte ratio in patients with small-cell lung cancer. British journal of cancer. 2014; 111:452-60.

28. Johnson DH, Greco FA, Strupp J, Hande KR, Hainsworth JD. Prolonged administration of oral etoposide in patients with relapsed or refractory small-cell lung cancer: a phase II trial. Journal of Clinical Oncology. 1990; 8:1613-7.

29. Albain KS, Crowley JJ, Leblanc M, Livingston RB. Determinants of improved outcome in small-cell lung cancer: an analysis of the 2,580-patient Southwest Oncology Group data base. Journal of Clinical Oncology. 1990; 8:1563-74.

30. Yip D, Harper PG. Predictive and prognostic factors in small cell lung cancer: current status. Lung Cancer. 2000; 28:173-85.

31. Foster NR, Mandrekar SJ, Schild SE, Nelson GD, Rowland KM Jr, Deming RL, Kozelsky TF, Marks RS, Jett JR, Adjei AA. Prognostic factors differ by tumor stage for small cell lung cancer: a pooled analysis of North Central Cancer Treatment Group trials. Cancer. 2009; 115:2721-31.

32. Pignon JP, Arriagada R, Ihde DC, Johnson DH, Perry MC, Souhami RL, Brodin O, Joss RA, Kies MS, Lebeau B. A metaanalysis of thoracic radiotherapy for small-cell lung cancer. New England Journal of Medicine. 1992; 327:1618-24.

33. Warde P, Payne D. Does thoracic irradiation improve survival and local control in limited-stage small-cell carcinoma of the lung? A meta-analysis. Journal of Clinical Oncology. 1992; 10:890-5.

34. Takada M, Fukuoka M, Kawahara M, Sugiura T, Yokoyama A, Yokota S, Nishiwaki Y, Watanabe K, Noda K, Tamura T. Phase III study of concurrent versus sequential thoracic radiotherapy in combination with cisplatin and etoposide for limited-stage small-cell lung cancer: results of the Japan Clinical Oncology Group Study 9104. Journal of clinical oncology. 2002; 20:3054-60.

35. Fried DB, Morris DE, Poole C, Rosenman JG, Halle JS, Detterbeck FC, Hensing TA, Socinski MA. Systematic review evaluating the timing of thoracic radiation therapy in combined modality therapy for limited-stage small-cell lung cancer. Journal of clinical oncology. 2004; 22:4837-45.

36. Murray N, Coy P, Pater JL, Hodson I, Arnold A, Zee B, Payne D, Kostashuk E, Evans W, Dixon P. Importance of timing for thoracic irradiation in the combined modality treatment of limited-stage small-cell lung cancer. The National Cancer Institute of Canada Clinical Trials Group. Journal of Clinical Oncology. 1993; 11:336-44. 
37. Turrisi AT, Kim K, Blum R, Sause WT, Livingston RB, Komaki R, Wagner H, Aisner S, Johnson DH. Twice-daily compared with once-daily thoracic radiotherapy in limited small-cell lung cancer treated concurrently with cisplatin and etoposide. New England Journal of Medicine. 1999; 340:265-71.

38. Bogart JA, Herndon JE, Lyss AP, Watson D, Miller AA, Lee ME, Turrisi AT, Green MR. 70 Gy thoracic radiotherapy is feasible concurrent with chemotherapy for limited-stage small-cell lung cancer: analysis of Cancer and Leukemia Group B study 39808. Int J Radiat Oncol Biol Phys. 2004; 59:460-8.

39. Miller KL, Marks LB, Sibley GS, Clough RW, Garst JL, Crawford J, Shafman TD. Routine use of approximately 60 Gy once-daily thoracic irradiation for patients with limitedstage small-cell lung cancer. Int J Radiat Oncol Biol Phys. 2003; 56:355-9.

40. Roof KS, Fidias P, Lynch TJ, Ancukiewicz M, Choi NC. Radiation dose escalation in limited-stage small-cell lung cancer. Int J Radiat Oncol Biol Phys. 2003; 57:701-8.

41. Bremnes RM, Sundstrom S, Aasebø U, Kaasa S, Hatlevoll R, Aamdal S, Norweigian Lung Cancer Study Group. The value of prognostic factors in small cell lung cancer: results from a randomised multicenter study with minimum 5 year follow-up. Lung cancer. 2003; 39:303-13.

42. Stokkel M, Van Eck-Smit B, Zwinderman A, Willems L, Pauwels E. The diagnostic value of pretreatment serum LDH in patients with limited disease small-cell lung carcinoma. The International journal of biological markers. $1996 ; 12: 162-7$.

43. Li J, Dai CH, Chen P, Wu JN, Bao QL, Qiu H, Li XQ. Survival and prognostic factors in small cell lung cancer. Medical Oncology. 2010; 27:73-81.

44. Brueckl WM, Herbst L, Lechler A, Fuchs F, Schoeberl A, Zirlik S, Klein P, Brunner TB, Papadopoulos T, Hohenberger W. Predictive and prognostic factors in small cell lung carcinoma (SCLC)-analysis from routine clinical practice. Anticancer research. 2006; 26:4825-32.

45. Byhardt RW, Hartz A, Libnoch JA, Hansen R, Cox JD. Prognostic influence of TNM staging and LDH levels in small cell carcinoma of the lung (SCCL). Int J Radiat Oncol Biol Phys. 1986; 12:771-7.

46. Ganz PA, Ma PY, Wang HJ, Elashoff RM. Evaluation of three biochemical markers for serially monitoring the therapy of small-cell lung cancer. Journal of Clinical Oncology. 1987; 5:472-9.

47. Wang X, Jiang R, Li K. Prognostic significance of pretreatment laboratory parameters in combined small-cell lung cancer. Cell biochemistry and biophysics. 2014; 69:633-40.

48. Yamanaka $\mathrm{T}$, Matsumoto $\mathrm{S}$, Teramukai S, Ishiwata $\mathrm{R}$, Nagai Y, Fukushima M. The baseline ratio of neutrophils to lymphocytes is associated with patient prognosis in advanced gastric cancer. Oncology. 2008; 73:215-20.
49. von Pawel J, Jotte R, Spigel DR, O'Brien ME, Socinski MA, Mezger J, Steins M, Bosquée L, Bubis J, Nackaerts K. Randomized phase III trial of amrubicin versus topotecan as second-line treatment for patients with small-cell lung cancer. Journal of Clinical Oncology. 2014; 32:4012-4019.

50. Garassino MC, Torri V, Michetti G, Dico ML, La Verde N, Aglione S, Mancuso A, Gallerani E, Galetta D, Martelli O. Outcomes of small-cell lung cancer patients treated with second-line chemotherapy: a multi-institutional retrospective analysis. Lung Cancer. 2011; 72:378-83.

51. Lara PN, Moon J, Redman MW, Semrad TJ, Kelly K, Allen JW, Gitlitz BJ, Mack PC, Gandara DR. Relevance of platinum-sensitivity status in relapsed/refractory extensivestage small-cell lung cancer in the modern era: a patientlevel analysis of southwest oncology group trials. Journal of Thoracic Oncology. 2015; 10:110-5.

52. Wang LJ, Liu XJ, Guan Y, Zhang CF, Wang P, Li Y, Guo QS. Optimal timing of radiotherapy with alternating/ sequential radio-chemotherapy for limited-stage small cell lung cancer. Asian Pacific Journal of Cancer Prevention. 2014; 15:5697-9.

53. Xu HN, Kadlececk S, Profka H, Glickson JD, Rizi R, Li LZ. Is higher lactate an indicator of tumor metastatic risk? A pilot MRS study using hyperpolarized 13 C-pyruvate. Academic radiology. 2014; 21:223-31.

54. Käsmann L, Janssen S, Rades D. Prognostic Factors Including the Expression of Thyroid Transcription Factor 1 (TTF1) in Patients Irradiated for Limited-disease Small Cell Lung Cancer. Anticancer Research. 2016; 36:3499-503.

55. Zhang CL, Ge SL, Yang N, Zhang JR, Tian DD. Elevated Serum Level of Angiopoietin-2 as a Potential Marker for Poor Prognosis in Small Cell Lung Cancer. Tohoku Journal of Experimental Medicine. 2015; 236:305-9.

56. Paesmans M, Sculier JP, Lecomte J, Thiriaux J, Libert P, Sergysels R, Bureau G, Dabouis G, Van Cutsem O, Mommen P. Prognostic factors for patients with small cell lung carcinoma: analysis of a series of 763 patients included in 4 consecutive prospective trials with a minimum followup of 5 years. Cancer. 2000; 89:523-33.

57. Ustuner Z, Saip P, Yasasever V, Vural B, Yazar A, Bal C, Ozturk B, Ozbek U, Topuz E. Prognostic and predictive value of vascular endothelial growth factor and its soluble receptors, VEGFR-1 and VEGFR-2 levels in the sera of small cell lung cancer patients. Medical Oncology. 2008; 25:394-9.

58. Kalemkerian GP, Gadgeel SM. Modern staging of small cell lung cancer. Journal of the National Comprehensive Cancer Network. 2013; 11:99-104.

59. Therasse P, Arbuck SG, Eisenhauer EA, Wanders J, Kaplan RS, Rubinstein L, Verweij J, Van Glabbeke M, van Oosterom AT, Christian MC. New guidelines to evaluate the response to treatment in solid tumors. Journal of the National Cancer Institute. 2000; 92:205-16. 